\title{
Epidemiology and etiology of meningioma
}

\author{
Joseph Wiemels • Margaret Wrensch • \\ Elizabeth B. Claus
}

Received: 1 July 2010/Accepted: 24 August 2010/Published online: 7 September 2010

(c) The Author(s) 2010. This article is published with open access at Springerlink.com

\begin{abstract}
Although most meningiomas are encapsulated and benign tumors with limited numbers of genetic aberrations, their intracranial location often leads to serious and potentially lethal consequences. They are the most frequently diagnosed primary brain tumor accounting for $33.8 \%$ of all primary brain and central nervous system tumors reported in the United States between 2002 and 2006. Inherited susceptibility to meningioma is suggested both by family history and candidate gene studies in DNA repair genes. People with certain mutations in the neurofibromatosis gene (NF2) have a very substantial increased risk for meningioma. High dose ionizing radiation exposure is an established risk factor for meningioma, and lower doses may also increase risk, but which types and doses are controversial or understudied. Because women are twice as likely as men to develop meningiomas and these tumors harbor hormone receptors, an etiologic role for hormones (both endogenous and exogenous) has been hypothesized. The extent to which immunologic factors influence
\end{abstract}

J. Wiemels $(\bowtie)$

Department of Epidemiology and Biostatistics, University of California San Francisco, Helen Diller Cancer Research Building, 1450 3rd Street, MC 0520, San Francisco,

CA 94158, USA

e-mail: joe.wiemels@ucsf.edu

M. Wrensch

Department of Neurological Surgery, Epidemiology

and Biostatistics, University of California San Francisco,

San Francisco, CA, USA

E. B. Claus

Department of Epidemiology and Public Health, Yale University

School of Medicine, New Haven, CT, USA

E. B. Claus

Brigham and Women's Hospital, Boston, MA, USA meningioma etiology has been largely unexplored. Growing emphasis on brain tumor research coupled with the advent of new genetic and molecular epidemiologic tools in genetic and molecular epidemiology promise hope for advancing knowledge about the causes of intra-cranial meningioma. In this review, we highlight current knowledge about meningioma epidemiology and etiology and suggest future research directions.

Keywords Meningioma - Epidemiology · Etiology · Risk factor · Ionizing radiation $\cdot$ Hormones

\section{Epidemiologic research on meningioma}

Compared to the malignant glial tumors, meningiomas are relatively understudied with regards to etiologic risk factors. The challenges to meningioma research are several: (i) as a relatively rare disease, large or multicenter studies are necessary for sufficient numbers; (ii) the long latency of meningioma of 20-30 years or more, exhibited most evidentially in studies with known doses of ionizing radiation [1], makes exposure ascertainment difficult due to recall bias; (iii) the prevalence of subclinical disease in up to $2.8 \%$ of the population, as suggested by autopsy studies [2, 3], indicates that the pool of susceptible persons are much larger than those with clinically confirmed diagnoses; and (iv) the problem of detection bias-many meningiomas are discovered incidentally via MRIs for conditions such as head trauma or sinus problems. These incidentally discovered meningiomas, and a significant portion of primarily discovered meningiomas are managed "conservatively," meaning by observation and not surgical removal. One way epidemiologists can minimize detection bias is to only ascertain cases who have undergone surgical removal and 
pathological confirmation, ensuring that cases have clinically-significant meningioma. Only a few epidemiologic studies of intracranial tumors to date have been adequately powered to study separately risk factors for meningioma. These include the large European cohorts such as the Interphone [4], and the Million Women Study in the United Kingdom [5]. Several large European country- or regionspecific case-control studies were spawned from the Interphone study [6-8]. In 2002, The Benign Brain Tumor Cancer Registries Amendment Act (H.R. 5204) was passed, mandating registration of benign brain tumors such as meningioma in the United States. This legislation has and will continue to enhance reporting of both incidence rates and survival times for patients with meningioma. Before this act, meningioma mortality rate estimates were hampered by incomplete reporting and potential selection biases with respect to the individuals who were included in the databases, as well as limited follow-up information. The better quality of new information affords exceptional opportunities to the research and clinical communities in the coming years.

\section{Population statistics}

The prevalence of pathologically-confirmed meningioma is estimated to be approximately $97.5 / 100,000$ in the United States with over 170,000 individuals currently diagnosed with this tumor [9]. Since a proportion of meningiomas are not surgically managed, these estimates are low. In addition, autopsy and imaging studies have estimated subclinical meningioma rates of up to $2.8 \%$ in women $[2,3]$. Data from the Central Brain Tumor Registry of the United States (CBTRUS) demonstrates a more than twofold higher incidence among females [age-adjusted incidence rate (per 100,000 person years) of 8.36 and 3.61 for females and males, respectively] [9]. The female:male ratio of approximately $2: 1$ may be inverted for rare pre-pubertal meningiomas [10, 11]. Atypical and malignant meningiomas comprise a small fraction of the total $(\sim 5 \%)$ and have a slight male predominance. Reported rates for Black NonHispanics are slightly higher (6.67) than for White NonHispanic and Hispanics (5.90 and 5.94, respectively) [9]. Age-specific incidence rates (Fig. 1) reveal increasing risk with age in both men and women. Increasing risk of meningioma over the past several decades noted in CBTRUS [9] may be an artifact of increasingly accurate reporting of this disease.

\section{Molecular etiology}

Meningioma cells exhibit a striking similarity to arachnoid cap cells, which are the likely tumor cell of origin. Despite

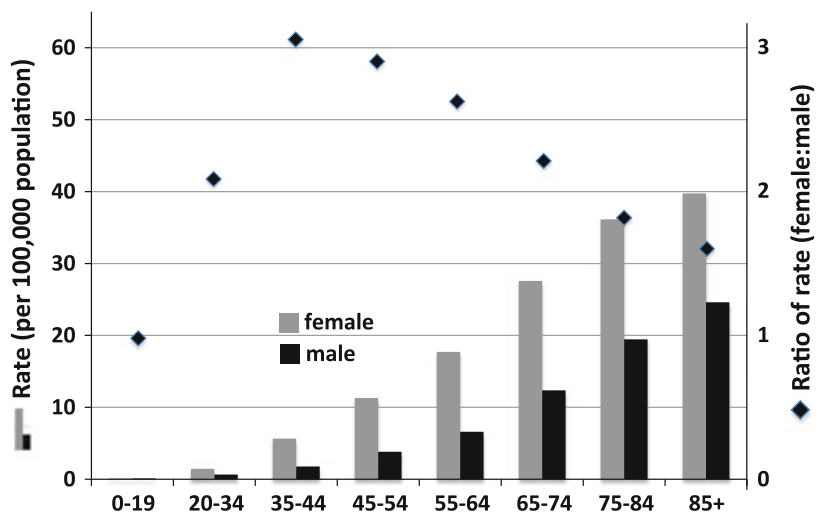

Fig. 1 Age and gender-specific incidence rates (per 100,000 population) for meningioma in the United States (2002-2006) (from reference 4). The left $Y$-axis scale refers to the bar graphs. The ratio of female to male incidence is indicated by a diamond at each age group, and the axis for the ratio is along the right hand side of the figure. The peak ratio of 3.15, female:male, is among the 35-44 year age group

the fact that meningioma has a benign pathophysiology in 95\% of cases, like carcinoma it always results from a clonal outgrowth derived from a single cell as exemplified by cytogenetic and array-comparative genomic hybridization (array-CGH) studies [12, 13]. Sporadic meningiomas are typically associated with one or more focal chromosomal deletion(s), and atypical and malignant grades tend to have multiple chromosomal copy number alterations consistent with the acquisition of "mutator" mutations which foster genomic instability [14]. Deletion and inactivation of NF2 on chromosome 22 is a predominant feature in sporadic meningiomas, and biallelic deletions are common [13]. Additional genes are likely involved as well, since loss of $N F 2$ occurs in only $1 / 3$ of patients who exhibit loss of heterozygosity of chromosome 22 [15]. Additional genomic regions which are recurrently lost in meningiomas include $14 q, 1 p, 6 q$, and 18q [16]. Although in one study, familial meningiomas did not demonstrate inherited copy number alterations, such families typically have a germline defect in $N F 2$ or other predispositing mutations [14]. Indeed, meningiomas are reported in families of several cancer predisposition syndromes including those involving the genes NF1, PTCH, CREBBP, VHL, PTEN, and CDKN2A (reviewed in [17]). Epigenetic aberrations in meningioma have not been thoroughly assessed, but one study suggests that DNA methylation events may impact meningioma biology more significantly than DNA copy number mutations [18]. Clearly, complexity of genetic aberrations in meningioma increases with tumor grade [19]. A relatively small number of mutations may be necessary for most meningiomas; however their slow growth makes long latency an issue, lending difficulty in identifying the source and timing of the initiating mutations, presenting a further complication for epidemiology studies. 


\section{Risk factors}

Ionizing radiation

At present, the primary environmental risk factor identified for meningioma is exposure to ionizing radiation (IR) with risks from six fold to ten fold reported [20-23]. At high dose levels, data exist for atomic bomb survivors showing a greatly increased risk for meningioma [21]. Evidence also exists for lower dose levels. In one of the most well-known studies of ionizing radiation and meningioma risk, children who were given radiation therapy for scalp ringworm in Israel between 1948 and 1960 (the Tinea Capitis Cohort), were observed to have a relative risk of almost 10 for meningioma [24]. A number of studies have linked the number of full-mouth dental radiographs to risk of meningioma (reviewed in [25]) although the sample sizes are limited and some subsequent studies (also small in size) did not replicate earlier studies [26, 27]. However, the most recent case/control study of 200 meningioma patients reported that patients reporting full-mouth X-rays had a significantly increased risk of meningioma (OR 2.06, 95\% CI 1.03, 4.17) although evidence for a dose response relation was lacking $(P$ for trend $=0.33$ ) [28]. Radiation therapy for intra-cranial tumors has also been linked to meningioma risk [22]. No recent large-scale studies of meningioma risk relative to ionizing radiation exist. Such studies are still highly relevant in the current era in which $\mathrm{X}$-ray doses for dental and other procedures have decreased, since new radiographic procedures with significant exposure risks have been introduced, including computed tomography (CT).

\section{Hormones}

An association between hormones and meningioma risk has been suggested by a number of findings including the increased incidence of post-pubertal disease in women versus men (2:1) with the highest ratio of 3.15:1 during the peak reproductive years (Fig. 1), the presence of estrogen, progesterone, and androgen receptors on some meningiomas, an association between breast cancer and meningiomas (see below), indications that meningiomas change in size during the luteal phase of the menstrual cycle and pregnancy, and the regression of multiple meningiomas in a patient following cessation of estrogen agonist therapy $[29,30]$. Despite these sentinel clues, meningioma is far from exhibiting a "hormone-fed" character in the clinic and epidemiologic measures of endogenous and exogenous hormones are not consistently associated with meningioma incidence.

Researchers have only begun to address the question of whether the use of exogenous hormones such as oral contraceptives (OC) and/or hormone replacement therapy (HRT) is associated with an increased risk of meningioma [5, 29, 31-35]. Data from two cohort studies and several case/control studies exist. In a case/control study nested within the Nurse's Health Study (NHS) (including 125 cases of meningioma), the relative risk of meningioma associated with hormone use for pre-menopausal women was $2.48(95 \%$ CI $1.29,4.77)$ when compared with postmenopausal women who had never used hormones [34]. For postmenopausal women who were hormone users the relative risk was 1.86 (95\% CI 1.07, 3.24). No excess risk was associated with past hormone use. No association was found for past or current use of oral contraceptives. Recently published data from a cohort study of 1.3 million women with a mean age of 55.9 and recruited from 1996 to 2001 (The Million Women Study) did not find an association between OC use (OR 1.06, 95\% CI 0.81-1.38 for use within the past five years) and meningioma risk $(n=390)$ but did not report results for HRT use [5]. In a large and recent case/control study, the Interphone Group reported an increased relative risk of meningioma $(n=178)$ among postmenopausal women for ever-use of HRT (OR 1.7, 95\% CI 1.0-2.8) [35]. Women who had used long-acting hormonal contraceptives also had an increased risk of meningioma; the odds ratio for at least 10 years of use was 2.7 (95\% CI 0.9-7.5). A retrospective records-based cohort study using the Mayo Clinic Jacksonville patient database between 1993 and 2003 confirms the positive NHS findings (OR 2.2, 95\% CI 1.9-2.6) of an association between HRT use and meningioma risk, comparing the frequency of HRT use among a case population of 1,390 with over 350,000 other women in the health system [31], while a case/control study including 219 meningioma cases identified from three Chicago area hospitals between 1987 and 1992 reports a protective effect for oral contraceptive use (OR $0.2,95 \%$ CI $0.0-0.8$ ) and a non-statistically significant protective effect associated with HRT use [32]. This latter study used the spouses of men with back pain as controls. Hence at present, there is limited statistical evidence of an increased risk of meningioma among users of oral contraceptives. Although not definitive, available data suggest an association between the use of hormone replacement therapy and increased meningioma risk. Further evaluation of exogenous hormone use in women with meningioma in a larger study is needed with particular attention to stratification by hormone composition (i.e. estrogen and/or progesterone), duration of and age at use as well as meningioma subgroups defined by tumor receptor expression (see below).

Researchers have also reported conflicting results when examining meningioma risk across categories of pregnancy, menstrual and anthropometric variables [5, 29, 3136]. When examining age at first menstrual period, 
investigators in the Nurse's Health Study observed a relative risk for meningioma for women with age at menarche 12-14 years of 1.29 (95\% CI 0.86-1.92) and for women with age at menarche after 14 years a relative risk of 1.97 (95\% CI 1.06-3.66) compared to those with menarche before age 12 [34]. A tendency for increased risk of meningioma for parous compared to non-parous women $(\mathrm{RR}=2.39$, 95\% CI 0.76-7.53) was also observed, although this value was not statistically significant [34]. In a second nested case/control study, Lambe et al. examined 1088 patients with meningioma within the Swedish Cancer Registry and matched to data from the Swedish Fertility Registry [36]. This group found no association between either parity or age at first birth and meningioma risk, however their analyses were not adjusted for other possible meningioma risk factors such as use of exogenous hormones or radiation exposure history. Data from the Interphone Study suggest that meningioma risk among women aged $<50$ years is increased with increasing number of livebirths (OR 1.8, 95\% CI 1.1-2.8 for three versus no livebirths) but found no association with menopausal status [35]. The Million Women Cohort reported an increasing risk of meningioma with increasing body mass index (OR $1.46,95 \%$ CI 1.11-1.91) but no association with number of pregnancies or age at first birth [5]. Body mass index, or more specifically body fat, is positively associated with aromatase activity resulting in higher endogenous estrogen exposure. An additional case/control study which included 219 cases found a protective effect for pregnancy which increased with number of pregnancies and age at first pregnancy [32]. Neither age at menarche or menopause were reported to show any effect in unadjusted analyses although menopause showed an increased risk (OR 2.0, 95\% CI 1.0-4.0) in adjusted analyses. In summary, the association between traditional hormone-based pregnancy and menstrual risk factors and meningioma risk is not consistent and deserve a more formal examination. Such an examination requires precise exposure assessments as well as an incorporation of a more thorough examination of biological features of individual patients data, including the expression of hormone receptors as described below, which may reveal subtypes with more clear evidence of hormone associations.

The functional significance of hormone receptors expressed on meningiomas is still controversial. Hormone receptors (estrogen, progesterone, and androgen) are expressed in an equivalent proportion of meningiomas derived from men and women [37], but their assessment has only been performed once in an epidemiologic study [38], and different laboratory methods for receptor expression capture widely varying proportions of positive patients [39-41]. A pilot study of 31 meningioma samples reported that a specific gene expression pattern appeared more strongly associated with PR status than with ER status [42]. Genes on the long arm of chromosome 22 and near the NF2 gene (22q12) were most frequently noted to have expression variation, with significant up-regulation in $\mathrm{PR}$ positive versus $\mathrm{PR}$ negative lesions suggesting a higher rate of 22q loss in PR negative lesions. Pathway analyses indicated that genes in collagen and extracellular matrix pathways were most likely to be differentially expressed by PR status [42]. The future incorporation of receptor expression into epidemiology studies may revolutionize the field as various molecular markers have done for cancers, for example hormone receptors in breast cancer. The field first needs to harmonize methodology to classify hormone receptors so that different studies can be compared and contrasted.

Head trauma

Head trauma has been suggested as a risk factor for meningioma since the time of Harvey Cushing, although the results across studies are not consistent. While some small case/control studies report an increased risk of meningioma associated with head trauma for both males and females [43, 44], other studies report no such association [45, 46]. In a cohort study of 228,055 Danish residents hospitalized for concussion, skull fracture or other head injury between 1977 and 1992 and followed for an average of eight years, the standardized incidence ratio (SIR) for meningioma after the first year was $1.2(95 \% \mathrm{CI}$ $0.8,1.7$ ) [47]. As mentioned above, associations of head trauma and meningioma may be an example of detection bias.

\section{Cell phone use}

The question of whether cell phone use is related to meningioma risk remains a question of great interest to the general public. At least ten studies have examined the association between cell phone use and tumors of the brain. At present, little evidence exists for an association between the two although sample sizes specific to meningiomas are relatively small, the follow-up time since commencement of cell-phone use is relatively short, and, in some instances, the measurement of cell-phone use is somewhat crude [48-50]. Newly reported data from the large Interphone study may also suffer some reporting bias; this study replicated earlier negative findings even for the highest exposed groups ( $>10$ years of heavy exposure) [4]. If the latency times of 17-36 years observed in ionizing radiation studies on the epidemiology of meningioma $[24,51]$ are taken as a guideline, the true extent of any possible relationship between cell phone use and meningioma risk may not be uncovered for decades and therefore this topic deserves continued attention. 
Association with breast cancer

An association between breast cancer and meningioma has been examined in several studies [29, 52, 53]. A number of explanations have been proposed for this association including the presence of common risk factors such as endogenous and exogenous hormones as well as shared genetic predisposition, including variants in DNA repair polymorphisms [52]. A review of the literature as well as an analysis of the association between breast cancer and meningioma using the western Washington State cancer registry data was provided by Custer et al. [53]. The relative risks observed across existing studies range between 1.5 and 2.0 with the majority statistically significant. Most of these studies have been conducted with tumor registry data and have relatively small sample sizes and none have been able to examine the association while controlling for risk factors which are likely to be shared by the two tumors, such as pregnancy and menstrual variables and exogenous hormone use. The fact that studies which identify risk of breast cancer in women who had meningioma, and vice versa, both have similar magnitude increased risk suggests that there is not a causal relationship between these tumors, rather that they share the same risk factors such as gender, age, hormone induction, and possibly other demographic variables [53].

\section{Occupation/diet/allergy}

Attempts to link specific chemicals with meningiomas in occupationally or industrially exposed groups have proved inconclusive (reviewed in [54]). An international case/ control study found no association between diet and meningioma ( $n=332$ ) [55]. Although a number of studies which examine the relationship between glial brain tumors and allergic disease such as asthma and eczema have found evidence for an association, little evidence has been found for such an association for meningioma $[6,8,56]$. A metaanalysis however demonstrated a significant inverse relationship of meningioma with allergy when excluding the single study that was most heterogeneous from the others (pooled $R R=0.84,95 \%$ CI $0.72-0.98, P=0.029$ ) [57], and a large recent study showed consistent inverse risk with asthma, hayfever, and eczema [7]. A study of innate immune genes did not find strong evidence of risk imparted by variants in such genes, but more investigation is warranted [58].

Family history of meningioma

Few studies have examined the relationship between meningioma risk and family history of meningioma. Malmer et al. examined cancer risk in spouses and first degree relatives of brain tumor patients in Sweden and reported that a meningioma diagnosis conferred a two fold increase in meningioma risk to first degree relatives (standardized incidence ratio [SIR] 2.2, 95\% CI 1.4, 3.1) but not to spouses of affected individuals [59]. An inverse association between risk and age at onset was observed with an SIR of 2.5 (95\% CI 1.5-4.0) for probands less than 50 years of age versus 1.3 (95\% CI 0.6-2.6) for probands older than 50 years of age. Similar analyses by Hemminki et al. using data from the Swedish and Norweigian Registry Databases, reveal an increased risk with increasing numbers of affected first degree relatives with persons having one or two first degree family members with meningioma (SIR 1.6, 95\% CI 1.3-42.0, and SIR 5.0, 95\% CI 0.9-14.8), respectively [60]. Despite the fact that up to one to three percent of the adult population may harbor a meningioma $[2,3]$, the total number of families with multiple members diagnosed with meningioma are relatively rare (indicating, in part, a wide spectrum of phenotypic expression with respect to clinical import and hence screening undertaken), and most such families are currently attributed to inherited NF2 mutations. At present no family based linkage or segregation analyses studies of meningioma have been reported.

\section{Molecular epidemiology}

In the most recent and largest study to date of genetic polymorphisms and meningioma risk, Interphone study investigators reported a statistically significant association with meningioma for 12 SNPs drawn from DNA repair genes [52]. These investigators examined 1,127 tagging SNPs selected to capture most of the common variation in 136 DNA repair genes as well as an additional 388 putative functional SNPs. These included 69 nonsynonymous coding SNPs that may identify functional changes in expressed proteins. A total of 631 cases and 637 controls drawn from five case/control series from the Interphone Study were genotyped. The Interphone study is a case/control project initially designed to examine the relationship between cell phone use and the risk of brain tumors, including meningioma. Study subjects are primarily Western European background. The group reported a novel and biologically intriguing association between meningioma risk and three variants in the gene that encodes breast cancer susceptibility gene 1-interacting protein 1 (BRIP1) (17q22). The most significant was SNP rs4968451 that maps to intron 4 of the gene (OR 1.61, 95\% CI 1.26-2.06 heterozygotes, OR 2.33, 95\% CI 1.25-4.34 homozygotes). The BRIPl gene is involved in the repair of DNA double-strand breaks by homologous recombination in a manner that depends on its association with BRCA1. Defects in BRIPl are linked to 
breast cancer susceptibility (as well as Fanconi anemia), leading researchers to speculate that the reported association between breast cancer and meningioma risk may be due to similar defects in DNA repair genes rather than/in addition to the previously assumed shared hormonal risk factors (such as hormone replacement therapy). This group also reported a statistically significant association between four variants in the ATM gene, a member of the phosphatidylinositol-3 kinase family known to be involved in homologous and nonhomologous DNA break repair, and meningioma risk. Previous groups have also noted significant associations between ATM variants for meningioma as well as breast cancer [23, 61]. These findings are again of interest in light of the associations between ionizing radiation and meningioma risk as well as between breast cancer and meningioma risk.

Additional candidate genes studies have suggested a role for genes in apoptotic pathways [62], and as discussed above, immune regulatory pathways [58] and meningioma risk. Earlier studies examined variants in phase II metabolic genes, which would impact response to environmental or occupational chemical exposures; a meta-analysis of these studies implicates a potential role for the detoxifying enzyme GSTT1 in modulating meningioma risk $(\mathrm{OR}=1.95,95 \%$ CI 1.02-3.79) [63]. The lack of replication/confirmation and low number of variants assessed in candidate genes studies distracts from knowledge on the true genetic susceptibility of meningioma, which awaits results from agnostic genome-wide association studies.

\section{Directions for future studies}

Because of its "benign" nature, research in meningioma epidemiology and etiology has lagged behind that for more malignant intracranial neoplasms. The study of risk factors for meningioma remains challenging, and there are currently few large-scale studies. The two main known risk factors-genetic predisposition and high dose radiation exposures-account for a small proportion of cases. Although a role for hormones is possible given the gender distribution of meningiomas, little specific or consistent data exist on hormonal risk factors. Epidemiologic tools may be used to collect and define appropriate subject data from well-characterized source populations, being mindful of detection or diagnostic bias in patient ascertainment, in an effort to delineate risk factors both for the overall group of meningioma patients as well as for specific subgroups. High quality follow-up data for sufficient time periods must be collected on meningioma patients to obtain representative estimates of sex- and age-specific rates for recurrence, quality of life and overall survival. In addition to the collection of data on environmental risk factors such as hormone use, new projects will need to consider the inclusion of information on relevant genetic variants derived from ongoing whole genome and gene pathway scans. In addition to exploring environmental and genetic factors for meningioma risk separately, the interaction between the two must be examined. For example, the integration of environmental risk factors such as oral contraceptive use or radiation exposure with information on genetic polymorphisms in steroid hormone or DNA repair genes may help researchers to understand the complex relationship between genetic susceptibility and environmental exposures in the development of meningioma. Given the large numbers of subjects needed to study such gene-environment interactions, especially within defined subsets of meningioma such as the rare atypical and malignant subtypes, collaborative, multi-center efforts between a variety of researchers will be needed, including experts from such fields as neurosurgery, epidemiology, genetics, statistics, and neuropathology.

Meningioma epidemiology and etiology will benefit from the increased size and quality of disease reporting to cancer registries, facilitated in the USA by the Benign Brain Tumors Act of 2002. This act has resulted in the formation of a multicenter meningioma consortium, which is matched by several large studies in Europe. These studies will facilitate a rapid and thorough investigation into the genetic susceptibility factors for meningioma via genome-wide association and whole genome sequencing in the near future. The collection of blood and tumor material must accompany such studies to facilitate the rational classification of the disease into etiologic subtypes to further specify genetic, immunologic, and environmental risk factors. Exposure assessments will continue to hinder progress in meningioma case-control studies, which are hampered by information bias because of poor or differential recall by study subjects, and the lack of verifiable biomarkers of exposure since information is obtained in retrospect. Future large cohort studies may help to ameliorate this problem, and large linked health databases may help study iatrogenic risk factors such as diagnostic and therapeutic ionizing radiation, and therapeutic hormone use.

Acknowledgments This work was supported by NIH R01 grants CA109745, CA109468, CA109461, CA108473, CA109475, CA52689, CA097257, the Brain Science Foundation, and the Meningioma Mommas.

Open Access This article is distributed under the terms of the Creative Commons Attribution Noncommercial License which permits any noncommercial use, distribution, and reproduction in any medium, provided the original author(s) and source are credited.

\section{References}

1. Sadetzki S, Modan B, Chetrit A, Freedman L (2000) An iatrogenic epidemic of benign meningioma. Am J Epidemiol 151: 266-272 
2. Krampla W, Newrkla S, Pfisterer W, Jungwirth S, Fischer P, Leitha T, Hruby W, Tragl KH (2004) Frequency and risk factors for meningioma in clinically healthy 75-year-old patients: results of the Transdanube Ageing Study (VITA). Cancer 100: $1208-1212$

3. Vernooij MW, Ikram MA, Tanghe HL, Vincent AJ, Hofman A, Krestin GP, Niessen WJ, Breteler MM, van der Lugt A (2007) Incidental findings on brain MRI in the general population. N Engl J Med 357:1821-1828

4. Group TIS (2010) Brain tumour risk in relation to mobile telephone use: results of the INTERPHONE international casecontrol study. Int J Epidemiol 39:675-694

5. Benson VS, Pirie K, Green J, Casabonne D, Beral V (2008) Lifestyle factors and primary glioma and meningioma tumours in the Million Women Study cohort. Br J Cancer 99:185-190

6. Berg-Beckhoff G, Schuz J, Blettner M, Munster E, Schlaefer K, Wahrendorf J, Schlehofer B (2009) History of allergic disease and epilepsy and risk of glioma and meningioma (INTERPHONE study group, Germany). Eur J Epidemiol 24:433-440

7. Schoemaker MJ, Swerdlow AJ, Hepworth SJ, van Tongeren M, Muir KR, McKinney PA (2007) History of allergic disease and risk of meningioma. Am J Epidemiol 165:477-485

8. Wigertz A, Lonn S, Schwartzbaum J, Hall P, Auvinen A, Christensen HC, Johansen C, Klaeboe L, Salminen T, Schoemaker MJ, Swerdlow AJ, Tynes T, Feychting M (2007) Allergic conditions and brain tumor risk. Am J Epidemiol 166:941-950

9. CBTRUS (2009-2010) CDTRUS Statistical Report: promary brain and central nervous system tumors diagnosed in eighteeen states in 2002-2006. Central Brain Tumor Registry of the United States, Hisdale

10. Li X, Zhao J (2009) Intracranial meningiomas of childhood and adolescence: report of 34 cases with follow-up. Childs Nerv Syst 25:1411-1417

11. Menon G, Nair S, Sudhir J, Rao BR, Mathew A, Bahuleyan B (2009) Childhood and adolescent meningiomas: a report of 38 cases and review of literature. Acta Neurochir (Wien) 151: 239-244; discussion 244

12. Al Saadi A, Latimer F, Madercic M, Robbins T (1987) Cytogenetic studies of human brain tumors and their clinical significance. II. Meningioma. Cancer Genet Cytogenet 26:127-141

13. Hansson CM, Buckley PG, Grigelioniene G, Piotrowski A, Hellstrom AR, Mantripragada K, Jarbo C, Mathiesen T, Dumanski JP (2007) Comprehensive genetic and epigenetic analysis of sporadic meningioma for macro-mutations on $22 \mathrm{q}$ and micro-mutations within the NF2 locus. BMC Genomics 8:16

14. Shen Y, Nunes F, Stemmer-Rachamimov A, James M, Mohapatra G, Plotkin S, Betensky RA, Engler DA, Roy J, Ramesh V, Gusella JF (2009) Genomic profiling distinguishes familial multiple and sporadic multiple meningiomas. BMC Med Genomics 2:42

15. Ragel BT, Jensen RL (2005) Molecular genetics of meningiomas. Neurosurg Focus 19:E9

16. Lee Y, Liu J, Patel S, Cloughesy T, Lai A, Farooqi H, Seligson D, Dong J, Liau L, Becker D, Mischel P, Shams S, Nelson S (2009) Genomic landscape of meningiomas. Brain Pathol 20:751-762

17. Simon M, Bostrom JP, Hartmann C (2007) Molecular genetics of meningiomas: from basic research to potential clinical applications. Neurosurgery 60:787-798 discussion 787-798

18. Jun P, Hong C, Lal A, Wong JM, McDermott MW, Bollen AW, Plass C, Held WA, Smiraglia DJ, Costello JF (2009) Epigenetic silencing of the kinase tumor suppressor WNK2 is tumor-type and tumor-grade specific. Neuro Oncol 11:414-422

19. Riemenschneider MJ, Perry A, Reifenberger G (2006) Histological classification and molecular genetics of meningiomas. Lancet Neurol 5:1045-1054
20. Hijiya N, Hudson MM, Lensing S, Zacher M, Onciu M, Behm FG, Razzouk BI, Ribeiro RC, Rubnitz JE, Sandlund JT, Rivera GK, Evans WE, Relling MV, Pui CH (2007) Cumulative incidence of secondary neoplasms as a first event after childhood acute lymphoblastic leukemia. JAMA 297:1207-1215

21. Preston DL, Ron E, Yonehara S, Kobuke T, Fujii H, Kishikawa M, Tokunaga M, Tokuoka S, Mabuchi K (2002) Tumors of the nervous system and pituitary gland associated with atomic bomb radiation exposure. J Natl Cancer Inst 94:1555-1563

22. Ron E, Modan B, Boice JD Jr, Alfandary E, Stovall M, Chetrit A, Katz L (1988) Tumors of the brain and nervous system after radiotherapy in childhood. N Engl J Med 319:1033-1039

23. Sadetzki S, Flint-Richter P, Starinsky S, Novikov I, Lerman Y, Goldman B, Friedman E (2005) Genotyping of patients with sporadic and radiation-associated meningiomas. Cancer Epidemiol Biomarkers Prev 14:969-976

24. Sadetzki S, Flint-Richter P, Ben-Tal T, Nass D (2002) Radiationinduced meningioma: a descriptive study of 253 cases. J Neurosurg 97:1078-1082

25. Preston-Martin S (1990) Descriptive epidemiology of primary tumors of the spinal cord and spinal meninges in Los Angeles County, 1972-1985. Neuroepidemiology 9:106-111

26. Ryan P, Lee MW, North B, McMichael AJ (1992) Amalgam fillings, diagnostic dental $\mathrm{X}$-rays and tumours of the brain and meninges. Eur J Cancer B Oral Oncol 28B:91-95

27. Schlehofer B, Blettner M, Becker N, Martinsohn C, Wahrendorf J (1992) Medical risk factors and the development of brain tumors. Cancer 69:2541-2547

28. Longstreth WT Jr, Phillips LE, Drangsholt M, Koepsell TD, Custer BS, Gehrels JA, van Belle G (2004) Dental X-rays and the risk of intracranial meningioma: a population-based case-control study. Cancer 100:1026-1034

29. Claus EB, Black PM, Bondy ML, Calvocoressi L, Schildkraut JM, Wiemels JL, Wrensch M (2007) Exogenous hormone use and meningioma risk: what do we tell our patients? Cancer 110: $471-476$

30. Vadivelu S, Sharer L, Schulder M (2010) Regression of multiple intracranial meningiomas after cessation of long-term progesterone agonist therapy. J Neurosurg 112:920-924

31. Blitshteyn S, Crook JE, Jaeckle KA (2008) Is there an association between meningioma and hormone replacement therapy? J Clin Oncol 26:279-282

32. Lee E, Grutsch J, Persky V, Glick R, Mendes J, Davis F (2006) Association of meningioma with reproductive factors. Int $\mathbf{J}$ Cancer 119:1152-1157

33. Wigertz A, Lonn S, Mathiesen T, Ahlbom A, Hall P, Feychting M (2006) Risk of brain tumors associated with exposure to exogenous female sex hormones. Am J Epidemiol 164:629-636

34. Jhawar BS, Fuchs CS, Colditz GA, Stampfer MJ (2003) Sex steroid hormone exposures and risk for meningioma. J Neurosurg 99:848-853

35. Wigertz A, Lonn S, Hall P, Auvinen A, Christensen HC, Johansen C, Klaeboe L, Salminen T, Schoemaker MJ, Swerdlow AJ, Tynes T, Feychting M (2008) Reproductive factors and risk of meningioma and glioma. Cancer Epidemiol Biomarkers Prev 17:2663-2670

36. Lambe M, Coogan P, Baron J (1997) Reproductive factors and the risk of brain tumors: a population-based study in Sweden. Int J Cancer 72:389-393

37. Korhonen K, Salminen T, Raitanen J, Auvinen A, Isola J, Haapasalo H (2006) Female predominance in meningiomas can not be explained by differences in progesterone, estrogen, or androgen receptor expression. J Neurooncol 80:1-7

38. Custer B, Longstreth WT Jr, Phillips LE, Koepsell TD, Van Belle $G$ (2006) Hormonal exposures and the risk of intracranial 
meningioma in women: a population-based case-control study. BMC Cancer 6:152

39. Black P, Carroll R, Zhang J (1996) The molecular biology of hormone and growth factor receptors in meningiomas. Acta Neurochir Suppl 65:50-53

40. Hsu DW, Efird JT, Hedley-Whyte ET (1997) Progesterone and estrogen receptors in meningiomas: prognostic considerations. J Neurosurg 86:113-120

41. Maxwell M, Galanopoulos T, Neville-Golden J, Antoniades HN (1993) Expression of androgen and progesterone receptors in primary human meningiomas. J Neurosurg 78:456-462

42. Claus EB, Park PJ, Carroll R, Chan J, Black PM (2008) Specific genes expressed in association with progesterone receptors in meningioma. Cancer Res 68:314-322

43. Phillips LE, Koepsell TD, van Belle G, Kukull WA, Gehrels JA, Longstreth WT Jr (2002) History of head trauma and risk of intracranial meningioma: population-based case-control study. Neurology 58:1849-1852

44. Preston-Martin S, Paganini-Hill A, Henderson BE, Pike MC, Wood C (1980) Case-control study of intracranial meningiomas in women in Los Angeles County, California. J Natl Cancer Inst 65:67-73

45. Annegers JF, Laws ER Jr, Kurland LT, Grabow JD (1979) Head trauma and subsequent brain tumors. Neurosurgery 4:203-206

46. Eskandary H, Sabba M, Khajehpour F, Eskandari M (2005) Incidental findings in brain computed tomography scans of 3000 head trauma patients. Surg Neurol 63:550-553 discussion 553

47. Inskip PD, Mellemkjaer L, Gridley G, Olsen JH (1998) Incidence of intracranial tumors following hospitalization for head injuries (Denmark). Cancer Causes Control 9:109-116

48. Inskip PD, Tarone RE, Hatch EE, Wilcosky TC, Shapiro WR, Selker RG, Fine HA, Black PM, Loeffler JS, Linet MS (2001) Cellular-telephone use and brain tumors. N Engl J Med 344: 79-86

49. Johansen C, Boice J Jr, McLaughlin J, Olsen J (2001) Cellular telephones and cancer-a nationwide cohort study in Denmark. J Natl Cancer Inst 93:203-207

50. Muscat JE, Malkin MG, Thompson S, Shore RE, Stellman SD, McRee D, Neugut AI, Wynder EL (2000) Handheld cellular telephone use and risk of brain cancer. JAMA 284:3001-3007

51. Neglia JP, Robison LL, Stovall M, Liu Y, Packer RJ, Hammond S, Yasui Y, Kasper CE, Mertens AC, Donaldson SS, Meadows AT, Inskip PD (2006) New primary neoplasms of the central nervous system in survivors of childhood cancer: a report from the Childhood Cancer Survivor Study. J Natl Cancer Inst 98:1528-1537

52. Bethke L, Murray A, Webb E, Schoemaker M, Muir K, McKinney P, Hepworth S, Dimitropoulou P, Lophatananon A,
Feychting M, Lonn S, Ahlbom A, Malmer B, Henriksson R, Auvinen A, Kiuru A, Salminen T, Johansen C, Christensen HC, Kosteljanetz M, Swerdlow A, Houlston R (2008) Comprehensive analysis of DNA repair gene variants and risk of meningioma. J Natl Cancer Inst 100:270-276

53. Custer BS, Koepsell TD, Mueller BA (2002) The association between breast carcinoma and meningioma in women. Cancer 94:1626-1635

54. Claus EB, Bondy ML, Schildkraut JM, Wiemels JL, Wrensch M, Black PM (2005) Epidemiology of intracranial meningioma. Neurosurgery 57:1088-1095 discussion 1088-1095

55. Terry MB, Howe G, Pogoda JM, Zhang FF, Ahlbom A, Choi W, Giles GG, Little J, Lubin F, Menegoz F, Ryan P, Schlehofer B, Preston-Martin S (2009) An international case-control study of adult diet and brain tumor risk: a histology-specific analysis by food group. Ann Epidemiol 19:161-171

56. Brenner AV, Linet MS, Fine HA, Shapiro WR, Selker RG, Black PM, Inskip PD (2002) History of allergies and autoimmune diseases and risk of brain tumors in adults. Int J Cancer 99:252-259

57. Linos E, Raine T, Alonso A, Michaud D (2007) Atopy and risk of brain tumors: a meta-analysis. J Natl Cancer Inst 99:1544-1550

58. Rajaraman P, Brenner AV, Neta G, Pfeiffer R, Wang SS, Yeager M, Thomas G, Fine HA, Linet MS, Rothman N, Chanock SJ, Inskip PD (2010) Risk of meningioma and common variation in genes related to innate immunity. Cancer Epidemiol Biomarkers Prev 19:1356-1361

59. Malmer B, Henriksson R, Gronberg H (2003) Familial brain tumours-genetics or environment? A nationwide cohort study of cancer risk in spouses and first-degree relatives of brain tumour patients. Int J Cancer 106:260-263

60. Hemminki K, Tretli S, Sundquist J, Johannesen TB, Granstrom C (2009) Familial risks in nervous-system tumours: a histologyspecific analysis from Sweden and Norway. Lancet Oncol 10: $481-488$

61. Malmer BS, Feychting M, Lonn S, Lindstrom S, Gronberg H, Ahlbom A, Schwartzbaum J, Auvinen A, Collatz-Christensen H, Johansen C, Kiuru A, Mudie N, Salminen T, Schoemaker MJ, Swerdlow AJ, Henriksson R (2007) Genetic variation in p53 and ATM haplotypes and risk of glioma and meningioma. J Neurooncol 82:229-237

62. Rajaraman P, Wang SS, Rothman N, Brown MM, Black PM, Fine HA, Loeffler JS, Selker RG, Shapiro WR, Chanock SJ, Inskip PD (2007) Polymorphisms in apoptosis and cell cycle control genes and risk of brain tumors in adults. Cancer Epidemiol Biomarkers Prev 16:1655-1661

63. Lai R, Crevier L, Thabane L (2005) Genetic polymorphisms of glutathione S-transferases and the risk of adult brain tumors: a meta-analysis. Cancer Epidemiol Biomarkers Prev 14:1784-1790 